Received: 2014.10 .14
Accepted: 2014.10 .26
Published: 2015.02 .01
Authors' Contribution:
A Study Design
B Data Collection
C Statistical Analysis
D Data Interpretation
E Manuscript Preparation
F Literature Search
G Funds Collection

\section{Radiation Safety Awareness Among Medical Staff}

\author{
Arkadiusz Szarmach ${ }^{1 \mathrm{ABCDEF}}$, Maciej Piskunowicz ${ }^{2 \mathrm{CDEF}}$, Dominik Świętońn ${ }^{1 \mathrm{CDE}}$, \\ Adam Muc $^{3 \mathrm{GE}}$, Gabor Mockałł ${ }^{1 \mathrm{BF}}$, Jarosław Dzierżanowski ${ }^{\mathrm{BCG}}$, Edyta Szurowska1⿴囗十 \\ ${ }^{1} 2^{\text {nd }}$ Department of Radiology, Medical University of Gdańsk, Gdańsk, Poland \\ $21^{\text {st }}$ Department of Radiology, Medical University of Gdańsk, Gdańsk, Poland \\ ${ }^{3}$ Polish-Japanese Institute of Information Technology in Gdańsk, Gdańsk, Poland \\ ${ }^{4}$ Chair \& Clinic of Neurosurgery, Medical University of Gdańsk, Gdańsk, Poland
}

Author's address: Arkadiusz Szarmach, $2^{\text {nd }}$ Department of Radiology, Medical University of Gdańsk, Smoluchowskiego 17 Str., 80-000 Gdańsk, Poland, e-mail: a.szarmach@gumed.edu.pl

\title{
Summary
}

Background: The common access to imaging methods based on ionizing radiation requires also radiation protection. The knowledge of ionizing radiation exposure risks among the medical staff is essential for planning diagnostic procedures and therapy.

Evaluation of the knowledge of radiation safety during diagnostic procedures among the medical staff.

Material/Methods:

The study consisted of a questionnaire survey. The questionnaire consisted of seven closed-ended questions concerning the knowledge of the effects of exposure to ionizing radiation as well as questions related to responder's profession and work experience. The study group included a total of 150 individuals from four professional groups: nurses, doctors, medical technicians, support staff. The study was carried out in the three largest hospitals in Gdańsk between July and October 2013.

Results: The highest rates of correct answers to questions related to the issue of radiation protection were provided by the staff of radiology facilities and emergency departments with 1-5 years of professional experience. The most vulnerable group in terms of the knowledge of these issues consisted of individuals working at surgical wards with 11-15 years of professional experience.

Conclusions: $\quad$ Education in the field of radiological protection should be a subject of periodic training of medical personnel regardless of position and length of service.

MeSH Keywords: $\quad$ Medical Staff • Radiation Dosage • Radiation Protection

PDF file: $\quad$ http://www.polradiol.com/abstract/index/idArt/892758

\section{Background}

The discovery of X-rays made by Wilhelm C. Roentgen on 8 November 1895 raised many hopes for application of this discovery not only in medicine, but also in other areas of everyday life, such as industry, agriculture or trade. Today, it is merely anecdotal that in the 1950s, X-ray machines were used in the US for example in shoe shops to assess the alignment of foot within the shoe.

In the early period of radiation diagnostics, no one suspected that ionizing radiation, despite its indisputable advantages, might have adverse effects on living organisms [1]. The pioneers of radiology were exposed to high doses of radiation, leading to various dermatoses, hematological disorders, cataract or cancer diseases. The doses absorbed by the first radiologists are estimated at $1 \mathrm{~Gy} /$ year [2]. The occurrence of the adverse effects of $\mathrm{X}$ rays had triggered scientific research in radiation protection. As a result, personal radiation protective equipment was introduced and legislations were passed that defined the limit values and established regulations for radiological protection of the medical staff and the patient [3-6]. 
Table 1. Questionnaire responses regarding radiation dose and associated risks.
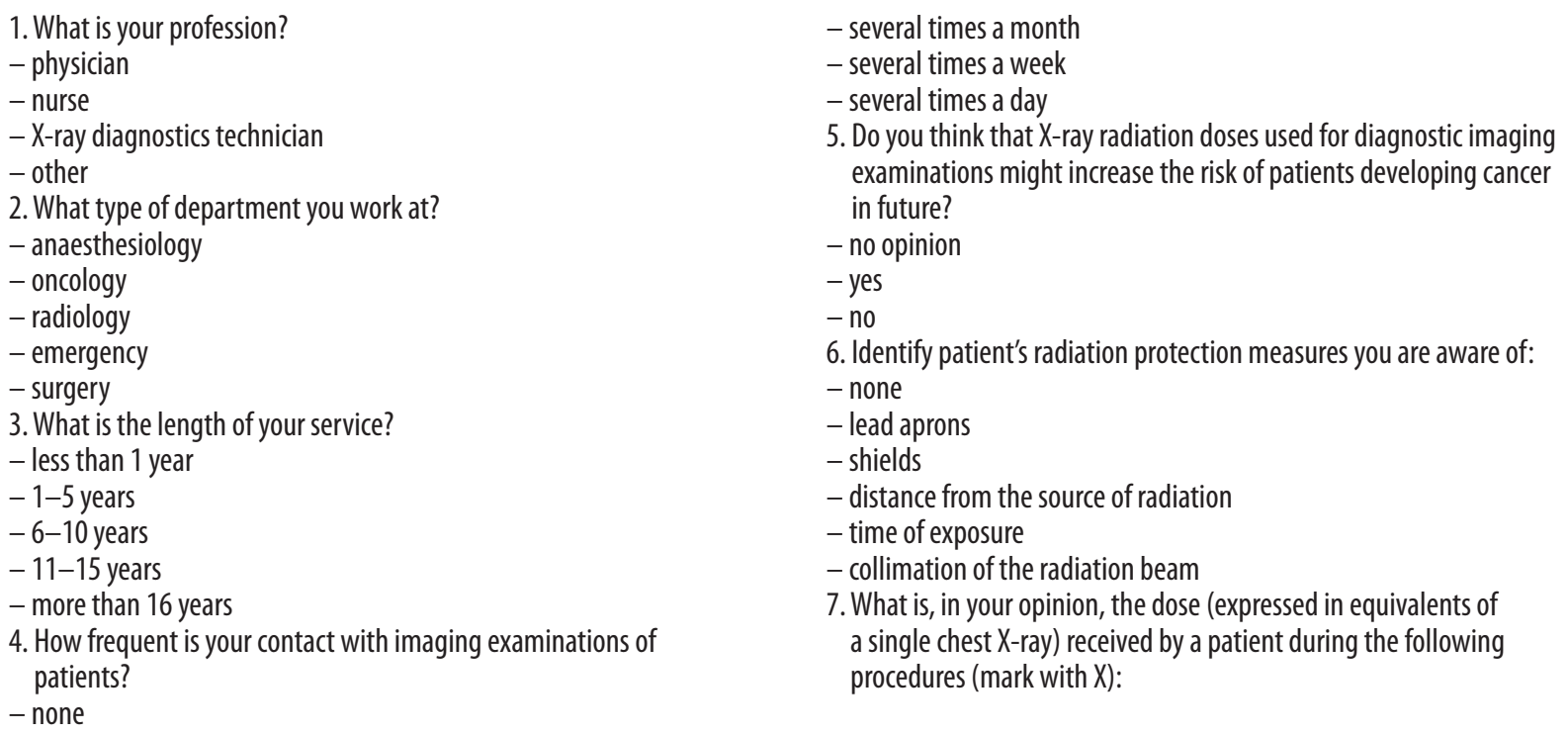

\begin{tabular}{|c|c|c|c|c|c|c|c|}
\hline Single chest X-ray equivalents & 0 & $10-49$ & $50-99$ & $100-199$ & $200-299$ & $300-499$ & $500-600$ \\
\hline Plain abdominal radiography & & & $x$ & & & & \\
\hline Extremity angiography & & & & & & $x$ & \\
\hline Head CT & & & & & $x$ & & \\
\hline Thoracic CT & & & & & & $x$ & \\
\hline Abdominal and pelvic CT & & & & & & & $x$ \\
\hline Voiding cystourethrogram & & & & $x$ & & & \\
\hline Abdominal ultrasound scan & $x$ & & & & & & \\
\hline Thyroid isotope scan & & $x$ & & & & & \\
\hline Brain MRI & $x$ & & & & & & \\
\hline
\end{tabular}

Correct answers are marked $X$ - estimated on the basis of European Commission guidelines [7].

\section{Objective}

The objective of this study was to evaluate the knowledge of radiation safety during diagnostic procedures among the medical staff of selected hospitals within the Tricity Area.

\section{Material and Methods}

A questionnaire survey consisting of 7 questions was conducted between July and October 2013 among 150 employees of the University Clinical Hospital in Gdańsk, Specialist Hospital in Gdańsk-Zaspa and Pomeranian Trauma Centre in Gdańsk

The survey consisted of closed-ended questions regarding the profession and the knowledge of the basic principles of radiation protection in diagnostics and treatment carried out using ionizing radiation. The objective of the survey questions was to verify the knowledge of the medical staff regarding selected topics on radiation protection and the doses of ionizing radiation received by the patients depending on the imaging technique being used. Also included in the survey were questions regarding the number of years of clinical experience, position, frequency of contact with X-ray radiation examinations and the department (Table 1).

The obtained results were subjected to analysis using the Microsoft Excel 2007 spreadsheet and the Statistica 8.5 software package.

In all tests, the assumed significance level was $P<0.05$.

\section{Results}

The most populous group within the study population were nurses - 66 (44\%) responders, followed by physicians - 51 (34\%) responders and medical technicians - 21 (14\%) responders. In addition, 12 (8\%) auxiliary staff members (others) were included in the study (Figure 1). 


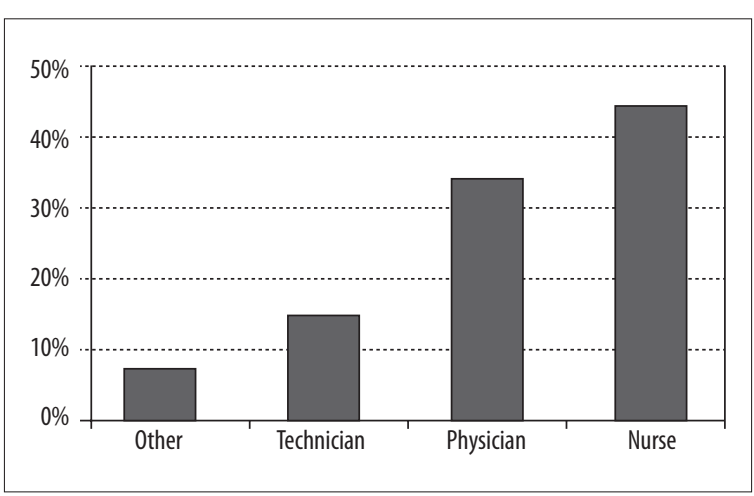

Figure 1. Distribution of the profession in the study group.

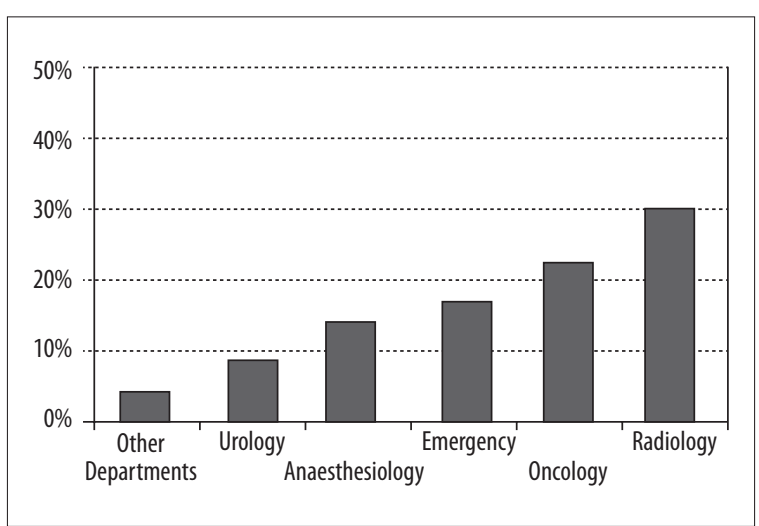

Figure 2. Distribution of the work place in the study group.

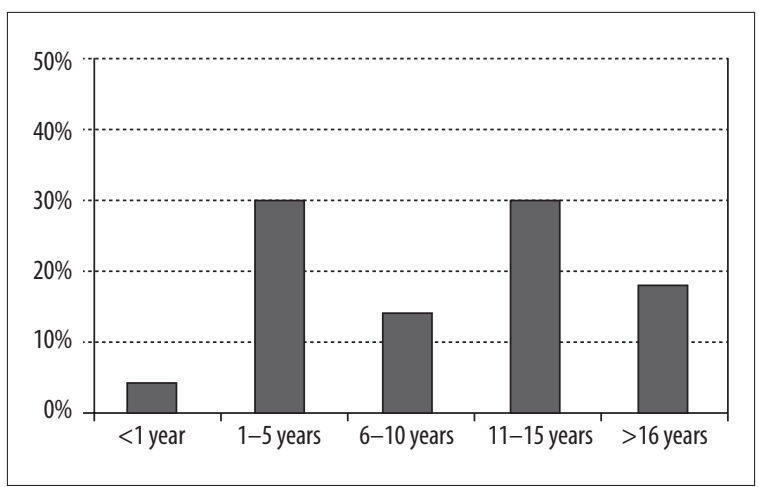

Figure 3. Distribution of the length of service in the study group.

The distribution of answers to the question regarding the hospital departments was as follows:

Anesthesiology - 21 responders, oncology - 33 responders, emergency - 27 responders, surgery -24 responders, radiology lab - 45 responders (Figure 2)

The most populous groups consisted of responders with 1-5 years (45 responders) and 11-15 years of clinical service (45 responders) (Figure 3).

With regard to the question regarding the contact with examinations that involved ionizing radiation, the most populous group consisted of 63 individuals who had everyday contact with various types of imaging diagnostics. Ninety responders gave positive answers to question 5 regarding potential carcinogenic effects of ionizing radiation.
Table 2. Replies of respondents concerning the knowledge of methods of radiation protection.

\begin{tabular}{cc}
\hline $\begin{array}{c}\text { Number of protection } \\
\text { measures identified }\end{array}$ & $\begin{array}{c}\text { Number of } \\
\text { responders }\end{array}$ \\
\hline 0 & 18 \\
\hline 1 & 33 \\
\hline 2 & 24 \\
\hline 3 & 36 \\
\hline 4 & 24 \\
\hline 5 & 12 \\
\hline 6 & 3 \\
\hline
\end{tabular}

Three of the proposed radiation protection measures were selected by the largest number of responders (36). At the same time, as many as six responders could not identify a single protective measure against ionizing radiation (Table 2).

The last question regarding ionizing radiation doses employed in individual diagnostic methods posed the biggest problem to the responders. The highest percentage of incorrect answers (132 responders, i.e. 87\% of the study group) pertained to the estimated number of single chest $\mathrm{X}$-ray equivalents of abdominal and pelvic CT scans.

The highest percentage of correct answers (108 responders, i.e. $78 \%$ of the study group) pertained to the exposure in patients subjected to ultrasound scans.

The obtained results were also used in the analysis of the knowledge of radiation protection depending on the length of service, place of service, and position.

The highest percentage of correct answers was provided by responders with $1-5$ years of service $(73 \%)$. The highest percentage of incorrect answers was provided by responders with $11-15$ years of service (14\%).

Responders employed at radiology departments and emergency departments had the best knowledge of radiation protection measures. The worst results were achieved by oncology staff (Figure 4).

According to the survey, nurses were the group with the worst knowledge of the analyzed aspects of ionizing radiation, regardless from the place of service (Figure 5).

At the same time, radiology and emergency department staff provided the most correct answers to questions regarding $\mathrm{X}$-rays and radiological protection.

\section{Discussion}

The safety of patients and staff is a priority of every diagnostic or therapeutic procedure involving ionizing radiation. Medical staff in contact with ionizing radiation must 


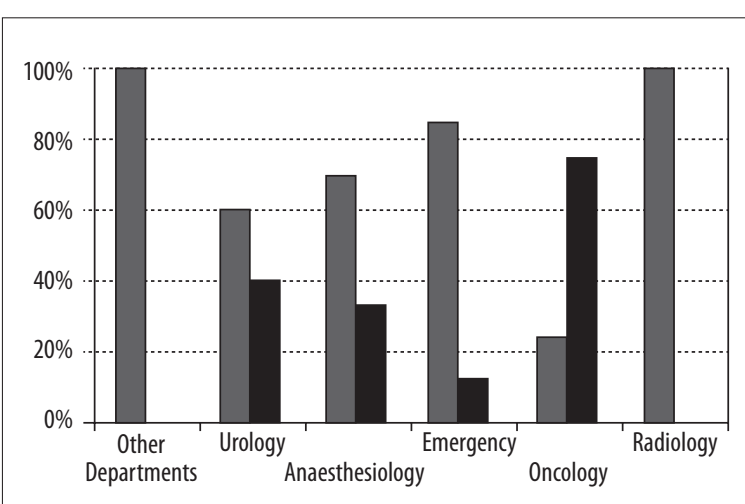

Figure 4. The knowledge of the radiological protection principles according to job place (wrong answers marked black, correct answers in gray).

proceed in accordance with the As Low As Reasonable Achievable (ALARA) principles. This includes performing the scans with possibly lowest doses of ionizing radiation allowing to obtain the desired diagnostic effect.

The number of studies regarding the awareness of radiological protection issues in medical staff regardless of position is low $[2,3,8,9]$.

The everyday clinical practice and incorrect, and sometimes contradictory provided by the medical staff have instigated us to attempt to determine the radiation protection awareness among the medical staff of selected hospitals in Gdańsk.

The study group purposefully included non-physicians (i.e. nurses, medical technicians and auxiliary staff members). This was due to the frequent contact of these medical professionals with patients before and during procedures involving ionizing radiation. According to the original premises, the study group should also be diverse in terms of the place and length of service.

The obtained results provided interesting information on the knowledge, expertise and convictions of medical professionals as regards radiation protection.

Good knowledge of the full spectrum of ionizing radiation effects among the employees of radiology departments is not surprising due to their specialist background.

Of note is the relatively good awareness of radiological protection within emergency departments, regardless of position (physician, nurse, auxiliary staff). It appears that this is due to the frequent contacts of these professionals with imaging diagnostics labs, resulting in better understanding of radiological procedures.

It is, however, very difficult to explain the low level of knowledge of the properties of ionizing radiation among oncology staff. This is all the more surprising that patients referred to diagnostic examinations from oncology units constitute a high percentage of all patients being diagnosed in every medical institution.

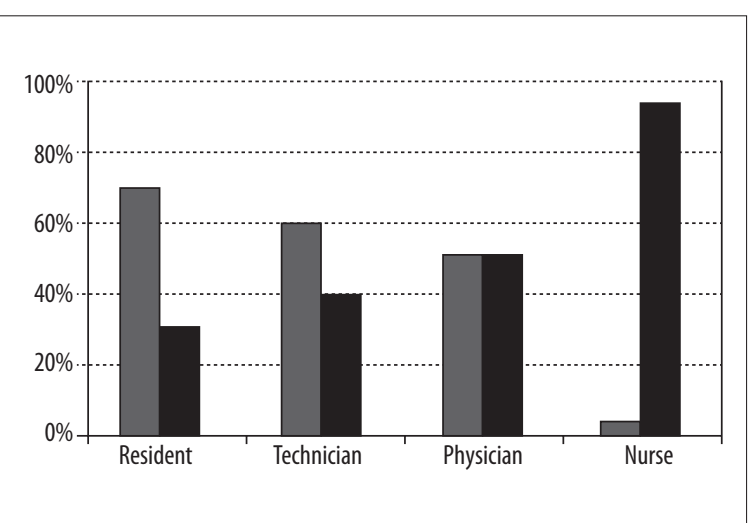

Figure 5. The knowledge of the radiological protection principles according to position (wrong answers marked black, correct answers in gray).

Another interesting conclusion is the low level of overall knowledge of radiographical procedures among the nursing staff. It is particularly curious in the context of care they provide to hospitalized patients and to their active participation in preparation for scheduled imaging examinations.

Of note is the high percentage of correct answers to most questions in employees with short service of 1-5 years as well as employees with 11-15 years of service.

Low level of knowledge of workers with 6-10 and over 16 years of service is alarming. It seems that this might be due to the low availability of radiological protection trainings and the reluctance towards changing professional habits among senior workers.

Radiation protection trainings are compulsory only in case of staff professionally exposed to radiation. The analysis revealed a relatively low level of knowledge on ionizing radiation among the study population. At the same time, it is interesting that the knowledge of the responders regarding the potential cancer outcomes of large doses of ionizing radiation was quite good, with correct answers being provided by $60 \%$ of responders.

Unfortunately, this knowledge seems to be acquired from media rather than trainings and specialist journals.

\section{Conclusions}

Despite the passing of more than 120 years from Roentgen's breakthrough discovery, protection against ionizing radiation continues to be an important problem in everyday practice of all medical professionals.

Although radiation diagnostics is an important and broadly used part of the therapeutic process, protection-related issues are usually addressed in a rather offhand manner.

In the era of increasing pro-health awareness within the society as well as of increasingly common claims filed against medical personnel, a better knowledge of radiation protection issues becomes an important element of professional expertise of not only radiologists and radiation 
therapists, but also other specialists as well as medium-level or auxiliary staff.
The conclusion from the conducted survey is that increased attention must be paid to thorough and systematic education of all healthcare professionals with regard to radiological protection.

\section{References:}

1. Bałturkiewicz Z, Musiałowicz T: 100 lat ochrony przed promieniowaniem jonizującym. Raport CLOR nr 136. Centralne Laboratorium Ochrony Radiologicznej, Warszawa 1999 [in Polish]

2. Kraska A, Bilski B: Narażenie pracowników ochrony zdrowia na promieniowanie jonizujacce a hipoteza Hormezy radiacyjnej. Medycyna Pracy, 2012; 63(3): 371-76 [in Polish]

3. Statkiewicz-Sherer M, Visconti P, Ritenour E: Radiation Protection in Medical Radiography. Mosby, St. Louis (USA), 1998; 123-24

4. The act of 29 November 2000 - Atomic Law (consolidated text Journal of Laws of 2007, No. 42 item 276, as amended by 2008, No. 93 item 583)

5. The Ordinance of the Council of Ministers of 18 January 2005 on ionizing radiation dose limits (Journal of Laws of 2005, No. 20 item 168)
6. Gostkowska B: Ochrona Radiologiczna - Wielkości, jednostki i obliczenia. Centralne Laboratorium Ochrony radiologicznej, Warszawa, 2007 [in Polish]

7. European Commission. Radiation protection 118: referral guidelines for imaging. Update March 2008. Available from: $h t t p: / / e c . e u r o p a$. eu/energy/nuclear/radioprotection/publication/doc/118 update en.pdf

8. Kew TY, Zahiah M, Zulkifli SZ et al: Doctor's Knowledge Regarding Radiation Dose and Its Associated Risks: Cross-sectional Stusy In a Tertiary Hospital In Malesia. Hong Kong J Radiol, 2012; 15: 71-79

9. Shilarkar S, Rennie A, Snow M et al: Doctor's knowledge of radiation exposure: questionnaire study. BMJ, 2003; 327: 371-72 